\title{
Insights Into The Origin of Selectivity For [2+2] Cycloaddition Step Reaction Involved In The Mechanism of Enantioselective Reduction of Ketones With Borane Catalyzed By A B-Methoxy Oxazaborolidine Catalyst Derived From (-)- $\beta-$ Pinene. A DFT And Combined Topological ELF, NCI And QTAIM Study
}

Hichem Sadrik Kettouche ( $\nabla$ hs.kettouche@gmail.com )

University of Constantine: Universite Constantine 1 https://orcid.org/0000-0002-8664-037X

Research Article

Keywords: Oxazaborolidine, Enantioselective reduction, [2+2] cycloaddition, DFT, ELF, NCI, QTAIM, MPWB1K, B3LYP, M06

Posted Date: July 14th, 2021

DOl: https://doi.org/10.21203/rs.3.rs-643212/v1

License: (c) (1) This work is licensed under a Creative Commons Attribution 4.0 International License. Read Full License 


\title{
Insights into the origin of selectivity for $[2+2]$ cycloaddition step reaction involved in the mechanism of enantioselective reduction of ketones with borane catalyzed by a $B$-methoxy oxazaborolidine catalyst derived from (-)- $\beta$-pinene. A DFT and combined topological ELF, NCI and QTAIM study
}

\author{
Hichem Sadrik Kettouche \\ Département de Chimie, Université Mentouri de Constantine. Route Aine El Bey, 25000 Constantine, Algérie \\ Email: hs.kettouche@gmail.com
}

\begin{abstract}
Theoretical studies on [2+2] cycloaddition step involved in the Enantioselective Reduction of ketones with borane catalyzed by a $B$-MethoxyOxazaborolidine Catalyst Derived from Pinene has been performed by means of the Density Functional Theory method (DFT) at MPWB1K /6-31G (d,p). The formation of the M5a(S) complexes via transition state $\mathbf{T S a}(\mathbf{S})$ was the more favorable pathway among other $[2+2]$ cycloaddition competing steps. The explanation of the formation of O-B and N-B through two-stage one-step mechanism was allowed by means of the electron localization function (ELF) topological analysis. NCI and QTAIM analysis of the two computed transition states $\mathbf{T S a}(\mathbf{S})$ and $\mathbf{T S a}(\mathbf{R})$ indicate that the difference between both in term of stability comes mainly from the orientation of the methanediyl group inside the pinene skeleton, which implies that $\mathrm{CH}-\mathrm{H} \ldots \mathrm{O}$ interaction found at $\mathbf{T S a}(\mathbf{S})$ is the great factor that makes it more stable than $\mathbf{T S a}(\mathbf{R})$.
\end{abstract}

Key Words: Oxazaborolidine; Enantioselective reduction; [2+2] cycloaddition ; DFT ; ELF ; NCI ; QTAIM ; MPWB1K ; B3LYP ; M06.

\section{Introduction}

The asymmetric reduction of prochiral ketones catalyzed by chiral oxazaborolidine derived from amino alcohol has been a powerful protocol to induce high enantioselectivety $^{1,2,3}$, where the absolute configuration of the major enantiomer was determined to be $R$ or $S$ under the influence of B and/or N-substitutes as expected for the pathway of the mechanism established by Corey et al ${ }^{2,4}$, which involves the following steps (see Scheme 1): formation of the M2' active catalyst and the catalyst-borane-ketone adduct M3; proton transfer from the borane moiety to the carbonyl carbon in M3 generates fourmembered ring(B(8)-N(3)-B(4)-O(7)) at the catalyst-alokoxybotrane adduct M5; formation of the final product (chiral secondary alcohol) and the release of the catalyst. Somewhat surprisingly, several computational studies on the mechanism of the reaction show the change 
of the selectivity of the oxazaborolydine-borane-ketone adduct complexes in the [2+2] cycloaddition step compared to that obtained in the remained steps involved in the mechanism $^{5,6}$. This finding urged me to disclose certain vital mechanistic insights into this step of the title reaction. Very recently I have considered an expanded conformational analysis of B-methoxy oxazaborolidine includes "M1a" and "M1b" conformations as preformed catalysts producing two catalytic cycles $\mathbf{a}$ and $\mathbf{b}^{7}$ (see Fig 1).

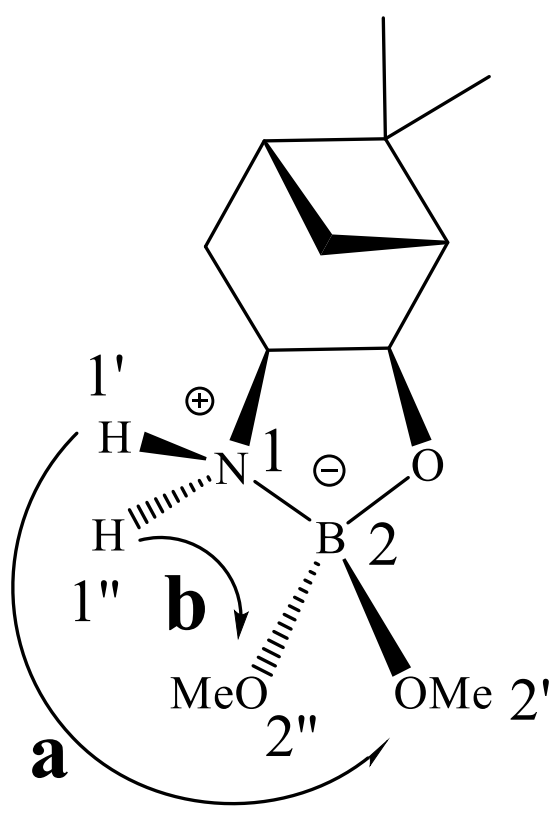

Fig. 1 The transfer of $\mathrm{H}\left(1^{\prime}\right)$ to $\mathrm{O}\left(2^{\prime}\right)$ and $\mathrm{H}\left(1^{\prime \prime}\right)$ to $\mathrm{O}\left(2^{\prime \prime}\right)$ in the catalyst cata

As shown in Fig. 1, the migration of $\mathrm{H}\left(1^{\prime}\right)$ from $\mathrm{N}(1)$ to $\mathrm{O}\left(2^{\prime}\right)$ pointed by the letter "a" gives rise, after removal of $\mathrm{MeOH}$ to M1a, while the other type of structure of oxazaborolidine M1b is obtained by transferring of $\mathrm{H}(1$ ') from $\mathrm{N}(1)$ to $\mathrm{O}(2$ ") which pointed by letter "b". Thus, there are two competing enantioselective cycles (mode a and b). 


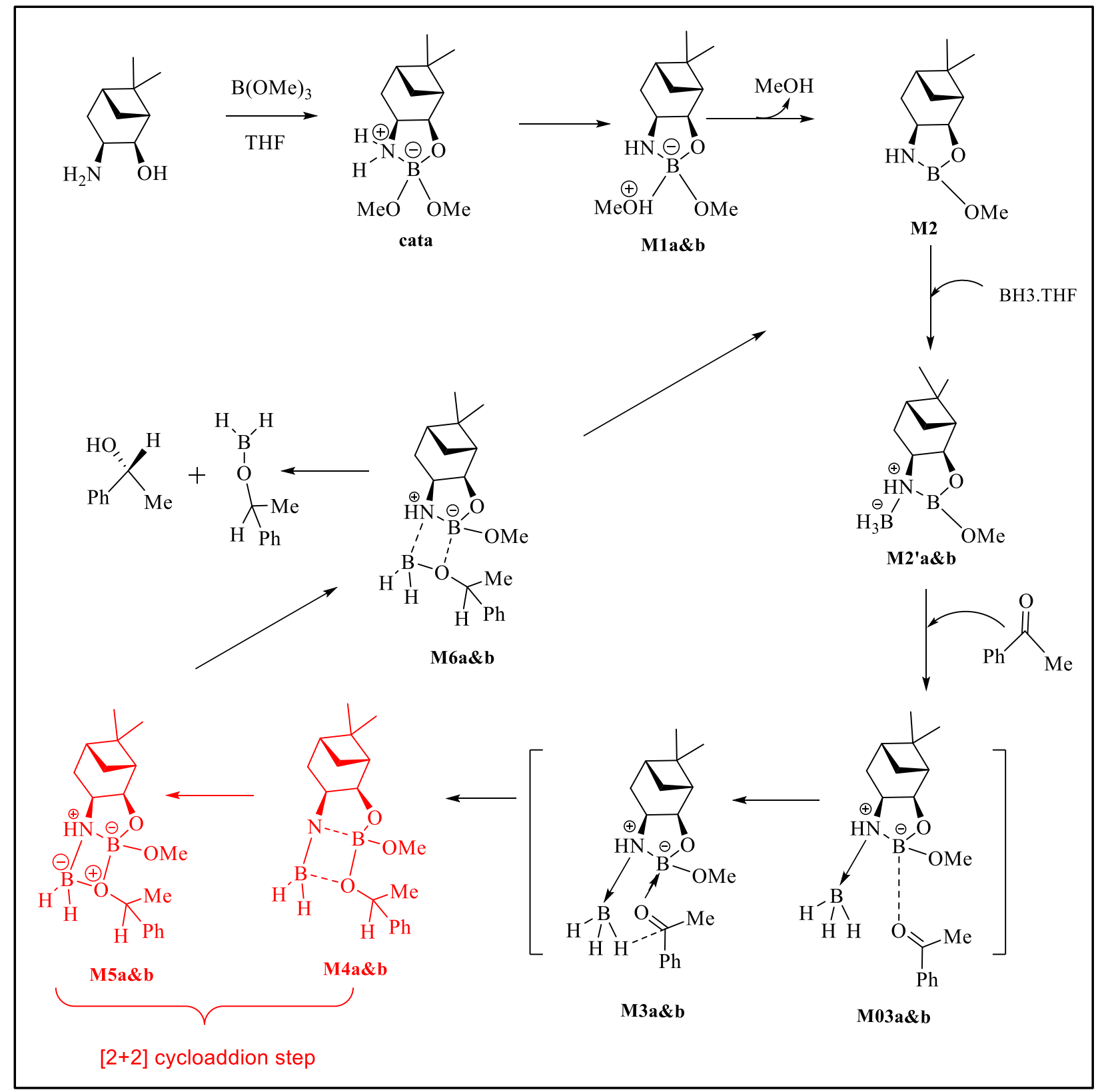

Scheme 1. Possible competing pathways for the title reaction

Therefore, the goal of this work is to understand the origin of the selectivity along the $[2+2]$ cycloaddition step involved in the reaction mechanism of the reduction of acetophenone as prochiral ketone with borane catalyzed by B-methoxy-oxazaborolidine derived from (1R,2S,3R,5R)-3-amino-6,6-dimethyl-2-hydroxy-bicyclo[3.1.1]-heptane. Moreover, there are still some key issues that need to be shed lighten and answered such as: (1) what is a suitable suite of density functional which can reproduce the correct and compatible selectivity? (2) What kind of active catalyst that will be involved in the reaction mechanism, consequently? (3) What is the conformation of the oxazaborolidine-boran-ketone adducts in the cycloaddition of the reaction? (4) Key factors governing the enantioselectivity of the title step 
of the reaction? All these raised questions prompt us to explore the role of the conformation of the catalyst-borane-keton adduct to induce the $S$-selectivity in this [2+2] cycloaddition step of the mechanism. We would predict and validate which atoms involved in the 22CA reaction would be the best electrophilic sites by using Houk's rule. Additionally, we perform an Electron localization function(ELF) ${ }^{8}$, noncovalent interaction index $(\mathrm{NCI})^{9}$ and Quantum Theory of atoms in Molecules(QTAIM) ${ }^{10}$ analysis to gain insight into the origin of selectivity of the title step by obtaining a chemical information relative to lone pair, bonding electron and especially investigate the hydrogen bonds (H-bonds) arising from the close contact of the $\mathrm{H}$ atom of the methanediyl group inside the pinene skeleton to atoms underneath in the oxazaborolidin ring.

\section{Models and computation}

In the present study, all theoretical calculations were performed using the GAUSSIAN $09^{11}$ suite of programs. All structures were optimized by employing the MPWB1K ${ }^{12}$ functional, which enhances thermodynamic calculations, together with the standard 6$31 \mathrm{G}(\mathrm{d}, \mathrm{p})^{13}$ basis set. These 22CA structures were further optimized by means of B3LYP ${ }^{14,15}$ and $\mathrm{M}_{06}{ }^{16}$ functionals, where the corresponding energies were compared with the previously mentioned MPWB1K one. The stationary points were analyzed by frequency calculations, testing that all reactants, intermediates, products and transition states have zero and only one imaginary frequency, respectively, and are verified by the internal reaction coordinate (IRC) 17,18 calculations, at the same level of theory, to identify all transition states. We then refined the energy by conducting single-point energy calculations for all the stationary points involved in the first step at a higher level of B3LYP/6-311++G(2df, 2pd)/IEF-PCM THF, M062X/6-311++G(2df, 2pd)/IEF PCM ${ }_{\mathrm{THF}} / / \mathrm{M} 06-2 \mathrm{X} / 6-31 \mathrm{G}(\mathrm{d}, \mathrm{p})$, and MPWB1K /6-311++G(2df, 2pd)/IEF-PCM ${ }_{\mathrm{THF}} / /$ MPWB1K /6-31G(d, p) level based on the B3LYP/6-31G(p, d), M062X/6-31G(p,d), M06-2X/6-31G(d, p), and MPWB1K /6-31G(p, d) optimized geometries in the gas phase, where IEF-PCM ${ }^{19 a, b}$ was used for the single points calculations to simulate the effects of solvent . It is worth noting that we will summarized the computational method of geometry optimization at the B3LYP/6-31G(d, p), M06-2X/6-31G(d, p), M06-2X/6-31G(d, $\mathrm{p})$, and MPWB1K /6-31G(p,d) level in Table 1, the single point energy calculated at the B3LYP/6-311++G(2df, 2pd)/IEF-PCM ${ }_{\mathrm{THF}}, \mathrm{M} 06-2 \mathrm{X} / 6-311++\mathrm{G}(2 \mathrm{df}, 2 \mathrm{pd}) / \mathrm{IEF} \mathrm{PCM}_{\mathrm{THF}}$ and MPWB1K /6-311++G(2df, 2pd)/IEF PCM ${ }_{\text {THF }}$ in Table 2, and the energy refinement in Table 3. 
Table 1., B3LYP/6-31G(d,p), M06/6-31G(d,p) and MPWB1K /6-31G(d,p) Total E (a.u) and relative energies $\Delta \mathrm{E}(\mathrm{kJ} / \mathrm{mol})$, in the gas phase of the stationary point SP involved in the [2+2] cycloaddition reaction along the reaction pathways (a and $\mathbf{b}$ ).

\begin{tabular}{|c|c|c|c|c|c|c|}
\hline & \multicolumn{2}{|c|}{ B3LYP } & \multicolumn{2}{|l|}{ M06 } & \multicolumn{2}{|c|}{ MPWB1K } \\
\hline & $\mathbf{E}$ & $\Delta \mathbf{E}$ & $\mathbf{E}$ & $\Delta \mathbf{E}$ & $\mathbf{E}$ & $\Delta \mathbf{E}$ \\
\hline $\operatorname{M1a}(\mathbf{S})$ & -1033.68651553 & & -1032.97455048 & & -1033.15708640 & \\
\hline $\operatorname{M1a}(\mathbf{R})$ & -1033.68192580 & & -1032.97597866 & & -1033.15959934 & \\
\hline M1b(S) & -1033.69202391 & & -1032.98312593 & & -1033.16797776 & \\
\hline $\operatorname{M1b}(\mathbf{R})$ & -1033.69680982 & & -1032.98724956 & & -1033.17297179 & \\
\hline $\mathbf{T S a}(\mathbf{S})$ & -1033.66439622 & 58.07 & -1032.96198010 & 33.00 & -1033.15094472 & 16.12 \\
\hline $\mathbf{T S a}(\mathbf{R})$ & -1033.66280448 & 50.20 & -1032.96145491 & 38.13 & -1033.15002231 & 25.14 \\
\hline TSb(S) & -1033.66789495 & 63.35 & -1032.96467543 & 48.44 & -1033.15037217 & 46.22 \\
\hline $\mathbf{T S b}(\mathbf{R})$ & -1033.67145749 & 66.56 & -1032.96713722 & 52.80 & -1033.15611826 & 44.25 \\
\hline M2a(S) & -1033.68429536 & 5.83 & -1032.98126266 & -17.62 & -1033.17872432 & -56.81 \\
\hline $\operatorname{M2a}(\mathbf{R})$ & -1033.68256875 & -1.69 & -1032.97967505 & -9.70 & -1033.17714210 & -46.06 \\
\hline M2b(S) & -1033.68777972 & 11.14 & -1032.98447205 & -3.53 & -1033.18163852 & -35.87 \\
\hline $\mathbf{M} 2 \mathbf{b}(\mathbf{R})$ & -1033.68890323 & 20.76 & -1032.98369791 & 9.32 & -1033.18151743 & -22.44 \\
\hline
\end{tabular}


Table 2. Comparison of the single-point energies calculated at B3LYP/6-311++G(2df, 2pd)/IEF-PCM $\mathrm{THF}_{\mathrm{TH}} / /$ B3LYP/6-31G(d, p), M06-2X/6-311++G(2df, 2pd)/IEF PCM $311++\mathrm{G}(2 \mathrm{df}, 2 \mathrm{pd}) / \mathrm{IEF}$ PCM $\mathrm{THF}_{\mathrm{HF}} / \mathrm{MP} 1 \mathrm{~W} / 6-31 \mathrm{G}(\mathrm{d}, \mathrm{p})$ Total E (a.u) and relative energies $\Delta \mathrm{E}(\mathrm{kJ} / \mathrm{mol})$, of the stationary point SP involved in the [2+2] cycloaddition reaction along the reaction pathways (a and $\mathbf{b})$.

\begin{tabular}{|c|c|c|c|c|c|c|}
\hline & \multicolumn{2}{|c|}{ B3LYP } & \multicolumn{2}{|l|}{ M06 } & \multicolumn{2}{|c|}{ MPWB1K } \\
\hline & $\mathbf{E}$ & $\Delta \mathbf{E}$ & $\mathbf{E}$ & $\Delta \mathbf{E}$ & $\mathbf{E}$ & $\Delta \mathbf{E}$ \\
\hline $\operatorname{M1a}(S)$ & -1033.99841174 & & -1033.26496359 & & -1033.44283384 & \\
\hline M1a(R) & -1033.99272126 & & -1033.26500755 & & -1033.44432460 & \\
\hline $\operatorname{M1b}(\mathbf{S})$ & -1034.00429741 & & -1033.27402925 & & -1033.45356296 & \\
\hline $\operatorname{M1b}(R)$ & -1034.01006063 & & -1033.27837707 & & -1033.45893569 & \\
\hline $\operatorname{TSa}(\mathbf{S})$ & -1033.97467172 & 62.33 & -1033.25111290 & 36.36 & -1033.43583219 & 18.38 \\
\hline $\mathbf{T S a}(\mathbf{R})$ & -1033.97430419 & 48.35 & -1033.25149929 & 35.47 & -1033.43629024 & 21.09 \\
\hline $\operatorname{TSb}(\mathbf{S})$ & -1033.97884869 & 66.82 & -1033.25493926 & 50.12 & -1033.42683420 & 70.17 \\
\hline $\operatorname{TSb}(\mathbf{R})$ & -1033.98215068 & 73.28 & -1033.25659682 & 57.18 & -1033.44080619 & 47.60 \\
\hline $\mathbf{M} 2 \mathbf{a}(\mathbf{S})$ & -1033.99444560 & 10.41 & -1033.27114838 & -16.24 & -1033.46364513 & -54.64 \\
\hline $\mathbf{M} 2 \mathbf{a}(\mathbf{R})$ & -1033.99228266 & 1.15 & -1033.26869936 & -9.69 & -1033.46154073 & -45.20 \\
\hline $\mathbf{M} 2 b(\mathbf{b})$ & -1033.99718268 & 18.68 & -1033.27359733 & -1.13 & -1033.46536747 & -30.99 \\
\hline $\mathbf{M} 2 \mathbf{b}(\mathbf{R})$ & -1033.99930174 & 28.25 & -1033.27418241 & 11.01 & -1033.46687270 & -20.84 \\
\hline
\end{tabular}


Table 3. Comparison of the energies refinement of the single-point energies calculated B3LYP/6-311++G(2df,

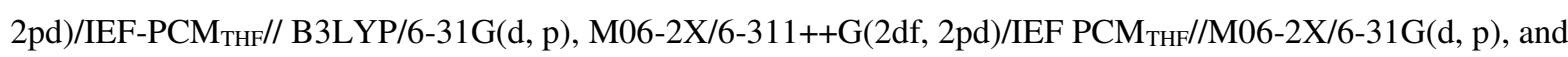

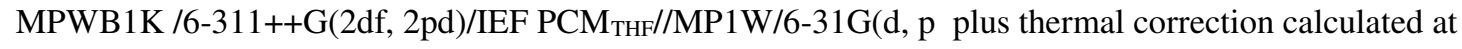
B3LYP/6-31G (d, p), M06/6-31G (d, p) and MPWB1K/6-31G (d, p), total E (a.u) and relative energies $\Delta \mathrm{E}$ $(\mathrm{kJ} / \mathrm{mol})$ of the stationary point SP involved in the [2+2] cycloaddition reaction along the reaction pathways (a and $\mathbf{b})$.

\begin{tabular}{|c|c|c|c|c|c|c|}
\hline & \multicolumn{2}{|c|}{ B3LYP } & \multicolumn{2}{|l|}{ M06 } & \multicolumn{2}{|c|}{ MPWB1K } \\
\hline & $\mathbf{E}$ & $\Delta \mathbf{E}$ & $\mathbf{E}$ & $\Delta \mathbf{E}$ & $\mathbf{E}$ & $\Delta \mathbf{E}$ \\
\hline $\operatorname{M1a}(\mathbf{S})$ & -1033.59705974 & & -1032.85772559 & & -1033.02613084 & \\
\hline M1a(R) & -1033.59244726 & & -1032.85781455 & & -1033.0234046 & \\
\hline M1b(S) & -1033.60331841 & & -1032.86642025 & & -1033.03566596 & \\
\hline $\operatorname{M1b}(\mathbf{R})$ & -1033.61085663 & & -1032.87461207 & & -1033.03935769 & \\
\hline $\operatorname{TSa}(\mathbf{S})$ & -1033.57043072 & 69.91 & -1032.84589190 & 31.07 & -1033.01775419 & 21.99 \\
\hline $\mathbf{T S a}(\mathbf{R})$ & -1033.57075819 & 56.94 & -1032.84607729 & 30.82 & -1033.01416424 & 24.26 \\
\hline $\operatorname{TSb}(\mathbf{S})$ & -1033.57546869 & 73.12 & -1032.85119026 & 39.99 & -1033.00766620 & 73.51 \\
\hline $\operatorname{TSb}(\mathbf{R})$ & -1033.57855168 & 84.82 & -1032.85372682 & 54.83 & -1033.02455419 & 38.87 \\
\hline M2a(S) & -1033.5879216 & 23.99 & -1032.86502038 & -19.15 & -1033.04160913 & -40.64 \\
\hline $\mathbf{M} 2 \mathbf{a}(\mathbf{R})$ & -1033.58601666 & 16.88 & -1032.86136336 & -9.32 & -1033.03795573 & -38.20 \\
\hline $\mathbf{M} 2 \mathbf{b}(\mathbf{S})$ & -1033.59104468 & 32.22 & -1032.86578433 & -1.67 & -1033.04236247 & -17.58 \\
\hline $\mathbf{M} 2 \mathbf{b}(\mathbf{R})$ & -1033.59323174 & 46.72 & -1032.86792141 & 17.57 & -1033.04482770 & -14.36 \\
\hline
\end{tabular}

The frontier molecular orbital (FMO) theory was used to interpret and investigate the reactivity and intramolecular interactions in concerted [2+2] cycladdition using houk's rule based on the HOMO and LUMO energies obtained within the Kohn-Sham scheme. The electronic chemical potential $\mu^{20}$ and the global electrophilicity index $\omega^{21}$ were calculated from the energies of the frontier molecular orbitals $\varepsilon_{\text {HOMO }}$ and $\varepsilon_{L U M O}$, as $\mu=\varepsilon_{\text {HOMO }}+\varepsilon_{L U M O} / 2$ and $\omega=\mu^{2} / 2\left(\varepsilon_{L U M O}-\varepsilon_{H O M O}\right)$.

Thermodynamic calculations such as enthalpies, entropies, and Gibbs free energies were computed at the standard statical thermodynamic at $298.15 \mathrm{~K}$ and $1 \mathrm{~atm}^{22}$. The electron localisation function (ELF) ${ }^{23}$ topological analysis was done with Multiwfn software using the MPWB1K/6-31G(d,p) wave functions of the pertinent steps selected from the IRC diagram. The evaluation of the reduced density gradient and low-gradient isosurfaces ${ }^{24,25}$ was used to 
perform Non-covalent interaction (NCI) ${ }^{26}$ analysis using Multiwfn ${ }^{27}$ package and visualized with $\mathrm{VMD}^{28}$. In NCI plots, green indicates weakly attractive while blue reveals strongly attractive. QTAIM ${ }^{29}$ were carried out with the same Multiwfn software and MPWB1K/6$31 \mathrm{G}(\mathrm{d}, \mathrm{p})$ wave functions previously mentioned in ELF.

\section{Result and discussion:}

This study focused on the studying the 22CA step involved in the reaction mechanism of enantioselective reduction of ketones with borane catalyzed by a B-methoxy oxazaborolidine catalyst, which structured into three sections: the first is dedicated to a comparison between the energies of the B3LYP, M06 and MPWB1K functionals as for to choose the suitable one for this study. The second section is allowed to study the [2+2] cycloaadition step involved in the catalytic mechanism, which include the study of: regioselectivity study based on Houk's rule, energy profiles and geometries analysis of the $[2+2]$ cycloaddition process, and nature of the molecular mechanism (ELF analysis). In the third one, the Origin of the S selectivity for the a catalytic cycle, which include Non-Covalent Interactions (NCI) in Transition States and Quantum Theory of Atoms in Molecules (QTAIM) Analysis, is studied in order to gain insight into the fact that $\mathbf{T S a}(\mathbf{S})$ is more favorable than $\mathbf{T S a}(\mathbf{R})$.

\subsection{Choice of the computational method}

In order to assess the suitable suite of density functional for realizing this study, we have performed a comparative assessment between the B3LYP, M06 and MPWB1K functionals. Table 1 shows the relative and total energies generated with the three levels of theory investigated. We can observe from Table 1 that the employing of B3LYP fails to find the right and a compatible configuration of the oxazaborolidine-borane-ketone adduct involved in the [2+2] cycloaddition step, where the $\mathbf{T S a}(\mathbf{R})$ is more stable than $\mathbf{T S a}(\mathbf{S})$ by $7.87 \mathrm{~kJ} / \mathrm{mol}$ which imply that the product of this 22CA step is of $R$ - selectivity. In the other hand, as illustrated in Table 1, the product energy of the more stable cycloadduct $\mathbf{M 5 a}(\mathbf{S})$ shows that the result obtained with M06 is higher $(-17,62 \mathrm{~kJ} / \mathrm{mol})$ than that obtained with MPWB1K ($56,81 \mathrm{~kJ} / \mathrm{mol}$ ) leading to a less exothermic reaction. Furthermore, the activation energies of the most favorable $\mathbf{T S a}(\mathbf{S})$ obtained with MPWB1K is $9.02 \mathrm{~kJ} / \mathrm{mol}$ bellow that of the second a approach (TSa $(\mathbf{R}))$, while the difference between $\mathbf{T S a}(\mathbf{S})$ and $\mathbf{T S a}(\mathbf{R})$ obtained with M06 is $5.13 \mathrm{~kJ} / \mathrm{mol}$. Furthermore, the accuracy of the chosen methods was tested by conducting 
additional calculations at the b3LYP/6-311++G(2df, 2pd)/IEF-PCM ${ }_{\mathrm{THF}} / / \mathrm{B} 3 \mathrm{LYP} / 6-31 \mathrm{G}(\mathrm{p}, \mathrm{d})$, M06-2X/6-311++G(2df， 2pd)/IEF $\quad \mathrm{PCM}_{\mathrm{THF}} / / \mathrm{M} 06-2 \mathrm{X} / 6-31 \mathrm{G}(\mathrm{d}, \mathrm{p})$, and $\mathrm{MPWB} 1 \mathrm{~K} / 6-$ $311++\mathrm{G}(2 \mathrm{df}, 2 \mathrm{pd}) / \mathrm{IEF}$ PCM $\mathrm{THF}_{\text {/ }}$ MPWB1K/6-31G(d,p) levels. As detailed in Tables $2 \& 3$ of the supporting information, the computational outcomes ( the single-point energies calculated with different levels, and the single-point energies plus thermal corrections to free energy calculated at the B3LYP/6-31G(d, p), M06-2X/6-31G(d, p), and MPWB1K /6-31G(d, p) level) illustrate that the same trend for the first step is clearly observed with different methods, indicating that the selected MPW1K functional with the 6-31G $(\mathrm{d}, \mathrm{p})$ basis set is the reliable and the suitable density functional for the both kinetic and thermodynamic studies of this 22CA step, that we will employ it to realize this work.

\subsection{Regioselectivity study based on Houk's rule}

To perform this preliminary study we have to define firstly which is the nucleophile and the electrophile agent within the single molecule involved in this intramolecular CA reaction and secondly, the atoms involved in this ICA.

We establish, according to the Tachibana and al scheme ${ }^{30,31,32}$, that the complex $\mathbf{M} 4 \mathbf{a}(\mathbf{S})$ consists of three areas corresponding fragment $\mathbf{A}$, fragment $\mathbf{B}$ and the bulky that links the region $\mathbf{A}$ and $\mathbf{B}$, where the two regions $\mathbf{A}$ and $\mathbf{B}$ are considered as nonhomogeneous electron gas having $\mu_{\mathrm{A}} \# \mu_{\mathrm{B}}\left(\mu_{\mathrm{A}}=-0.142\right.$ and $\left.\mu_{\mathrm{B}}=-0.118\right)$ (Fig 2, table 4). Then we study the chemical reactivity of IMCA by evaluating the reactivity indices, namely the electronic chemical potential $\mu$ and the global electrophilicity index $\omega$. 


\section{Bulky of union}

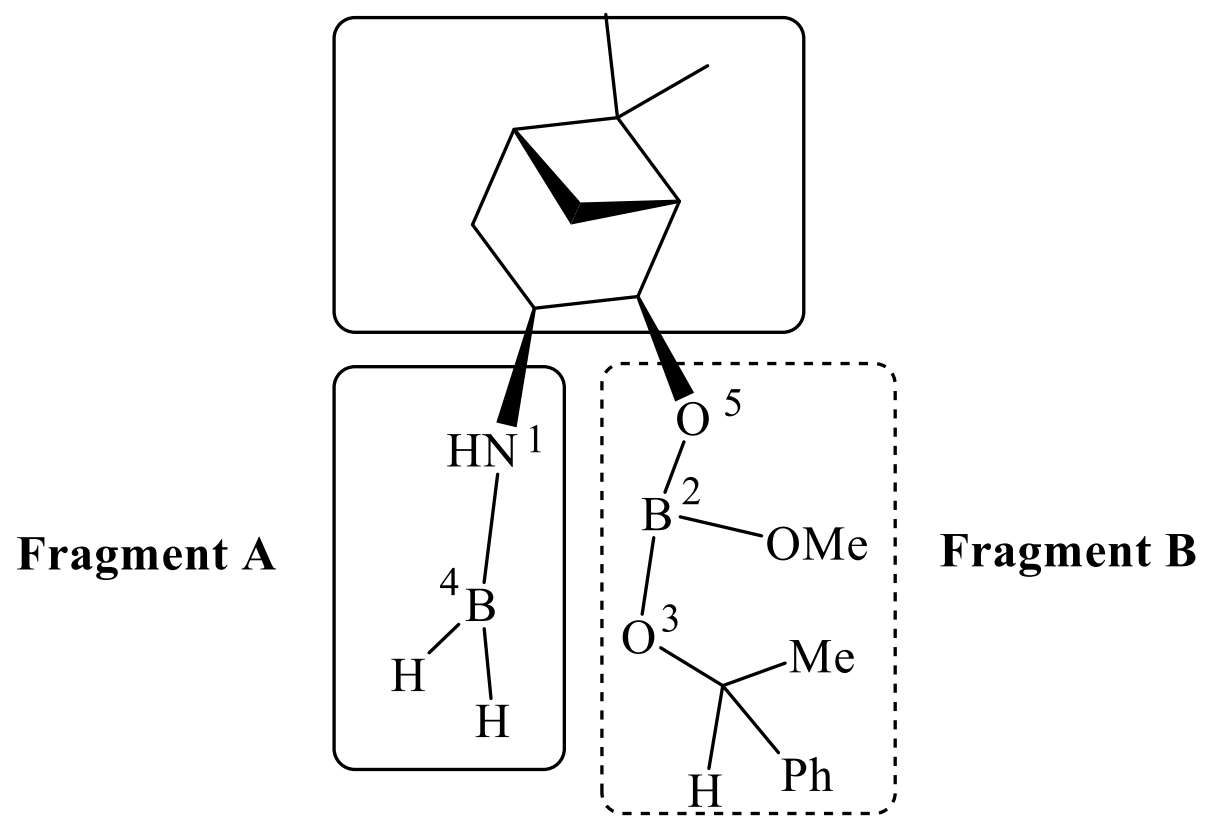

Fig. 2 Fragmentation scheme for the intramolecular [2+2] cycloaddition reaction of the reduction of acetophenone with borane catalysed by a B-methoxy oxazaborolidine

Based on the Houk's rule ${ }^{33}$, the IMCA reaction can be explained according to that "large-large and small-small FMO interactions are more favored than that of large-small and small-large FMO interactions." The FMO study of the intramolecular cycloadditionn (IMCA) demonstrates that the principle interaction takes place between the HOMO of the fragment $\mathbf{B}$ and the LUMO of the fragment A. Additionally, FMO coefficients presented in Table 4 clearly shows that the most favored large-large interaction occurs between $\mathrm{O}(3)$ of the fragment $\mathbf{B}$ and $\mathrm{B}(4)$ of the fragment $\mathbf{A}$, while the small-small interaction done between $\mathrm{B}(2)$ of the fragment $\mathbf{B}$ and $\mathrm{N}(1)$ of the fragment $\mathbf{A}$.

Table 4 The FMO energies (a.u.), electronic chemical potential (a.u.), and global electrophilicity index (a.u.) indices for the reactants

\begin{tabular}{ccccc}
\hline Reactant & HOMO & LUMO & $\mu$ & $\omega$ \\
\hline Frg A & -0.34434 & 0.06020 & -0.142 & 0.025 \\
Frg B & -0.27251 & 0.03684 & -0.118 & 0.022 \\
\hline
\end{tabular}

On the other hand, as shown in table 5, the large value of electronic chemical potential $\mu$ and the small one of the nucleophilic index $\omega$ for the fragment $\mathbf{B}$ regarding those of the 
fragment $\mathbf{A}$, indicates that the Fragment $\mathbf{B}$ act as nucleophile whereas the fragment $\mathbf{A}$ considered as electrophile, this finding is in line with the FMO study.

Table 5 FMOs coefficients of fragments $\mathbf{A}$ and $\mathbf{B}$

\begin{tabular}{ccccccc}
\hline Reactants & \multicolumn{7}{c}{ LUMO } \\
\hline Frag A & $\mathrm{N}(1)$ & & $\mathrm{B}(4)$ & $\mathrm{N}(1)$ & & $\mathrm{B}(4)$ \\
& 0,43701 & & 0,10950 & -0.28303 & & 0.43234 \\
& & HOMO & & & LUMO & \\
Frag B & $\mathrm{O}(3)$ & $\mathrm{B}(2)$ & $\mathrm{O}(5)$ & $\mathrm{O}(3)$ & $\mathrm{B}(3)$ & $\mathrm{O}(5)$ \\
& 0.04667 & 0.00522 & -0.01197 & 0.01194 & 0.03060 & -0.01406 \\
\hline
\end{tabular}

\subsection{Energy profile and geometries analysis of the $[2+2]$ cycloaddition process.}

As illustrated in Fig 1, there are two possible kinds of oxazaborolidine M1a and M1b can be involved in the mechanism reactional of the enantioselective reduction of acetophenone with borane catalyzed by oxazaborolidine, which imply to rise two competing channels (channels a and b) for the $[2+2]$ cycloaddition step each one has two stereoselective pathways (S \& R), in which the kind of catalyst (M1) with its structure exerts a great effect on the reaction. Thus, there are four pathways involved in this $22 \mathrm{CA}$ reaction.

The formation of the four-membered ring $(\mathrm{N}(1)-\mathrm{B}(2)-\mathrm{O}(3)-\mathrm{B}(4))$ occurs through the coordination between the carbonyl oxygen of aromatic ketone and the $\mathrm{B}(4)$ site. In this reaction, the catalyst-borane-acetophenone adducts $\mathbf{M 4}(\mathbf{a S}, \mathbf{a R}, \mathbf{b S}, \mathbf{b R})$ are transformed into the catalyst-alkoxyborane adducts $\mathbf{M 5}(\mathbf{a S}, \mathbf{a R , b S , b R})$ via TS(aS,aR,bS,bR) as shown in Scheme 1 and Fig.3 The distance of newly formed bonds $\mathrm{N}(1)-\mathrm{B}(2)$ and $\mathrm{B}(4)-\mathrm{O}(3)$ changes from 2.189/2.060 $\AA$ in $\mathbf{T S a}(\mathbf{S}), 2.127 / 2.129 \AA$ in $\mathbf{T S a}(\mathbf{R}), 2.377 / 1.814 \AA$ in $\mathbf{T S b}(\mathbf{S})$ and $2.201 / 1.980 \AA$ in $\mathbf{T S b}(\mathbf{R})$, to $1.600 / 1.549 \AA$ in $\mathbf{M 5 a}(\mathbf{S}), 1.575 / 1.550 \AA$ in $\mathbf{M 5 a}(\mathbf{R})$, 1.565/1.548 in $\mathbf{M 5 b}(\mathbf{S})$ and 1.585/1.546 $\AA$ in $\mathbf{M 5} \mathbf{b}(\boldsymbol{R})$, respectively, which demonstrate that the $\mathrm{B}(1)-\mathrm{N}(2)$ and $\mathrm{O}(3)-\mathrm{B}(4)$ bonds have completely formed in $\mathbf{M 5}$ (aS,a $\boldsymbol{R}, \mathbf{b S}, \mathbf{b} \boldsymbol{R})$, allowing the construction of the $(\mathrm{B}(1)-\mathrm{N}(2)-\mathrm{O}(3)-\mathrm{B}(4))$ 4-membered ring. The distances of the $\mathrm{N}(1)$ $\mathrm{B}(4)$, and $\mathrm{B}(2)-\mathrm{O}(3)$ bonds are 1.435 , and $1.406 \AA$ for $\mathbf{T S a}(\boldsymbol{S}), 1.436,1.400 \AA$ for $\mathbf{T S a}(\mathbf{R})$, 1.450, $1.412 \AA$ for $\mathbf{T S b}(\mathbf{S})$ and 1.440, $1.412 \AA$ for $\mathbf{T S b}(\boldsymbol{S})$ as illustrated in Fig 3. It is emphasized here that these geometric parameters point to synchronous $\mathrm{N}(1)-\mathrm{B}(2) \sigma$ and $\mathrm{O}(3)$ - 
$\mathrm{B}(4) \sigma$ bonds formation process of this $[2+2]$ cycloaddition reaction in along the transition states $\mathbf{T S a}(\mathbf{R})$ and slightly asynchronous in $\mathbf{T S a}(\mathbf{S})$, in which the formation of the $\mathrm{O}(3)-\mathbf{B}(4)$ bond is slightly advance the formation of $\mathrm{N}(1)-\mathrm{B}(2)$ one, but an asynchronous one along the $\operatorname{TSb}(\mathbf{S})$ and $\mathbf{T S b}(\mathbf{R})$.

From the Table 1, the MPWB1K/6-31G(d,p) activation energies related to this [2+2] cycloaddition reaction via transition states $\mathbf{T S}(\mathbf{a} \boldsymbol{S}, \mathbf{a} \boldsymbol{R}, \mathbf{b S}, \mathbf{b R})$ are 16.12/25.14/46.22/44.25 $\mathrm{kJ} / \mathrm{mol}$ respectively, indicating that the first step should be the most favorable process. Furthermore, the energies of products $\mathbf{M 5}(\mathbf{a} S, \mathbf{a} \boldsymbol{R}, \mathbf{b} S, \mathbf{b} \boldsymbol{R})$ are $56.81 / 46.06 / 35.87 / 22.44 \mathrm{~kJ} / \mathrm{mol}$ lower than that of complexes $\mathbf{M} 4(\mathbf{a} S, \mathbf{a} R, \mathbf{b S}, \mathbf{b} R)$, respectively. Therefore, the reactions involved in the 22CA process via transition states $\mathbf{T S}(\mathbf{a} S, \mathbf{a} R, \mathbf{b S}, \mathbf{b} R)$ is an exothermic process, which makes the formation of $\mathbf{M 5}(\mathbf{a} S, \mathbf{a} R, \mathbf{b} S, \mathbf{b} \boldsymbol{R})$ irreversible (see Table 1). This finding accounts for the complete $S$-selectivity.

On the other hand, as listed in the Table 6, the activation enthalpy values associated with 22CA process illustrates that the more favorable pathway is related to the $\mathbf{T S a}(\mathbf{S})(\Delta \mathrm{H}=$ $8.97 \mathrm{~kJ} / \mathrm{mol}$ ), which is in line with what was obtained in electronic energies. An additional entropic contribution to the enthalpy augments the activation Gibbs free energy of these reactive transition states involved in the $22 \mathrm{CA}$ to $13.12 \mathrm{~kJ} / \mathrm{mol}$ for $\mathbf{T S a}(\mathbf{S}), 19.97 \mathrm{~kJ} / \mathrm{mol}$ for $\mathbf{T S a}(\mathbf{R})$ and to $41.93 \mathrm{~kJ} / \mathrm{mol}$ for $\mathbf{T S b}(\mathbf{S})$, while this Gibbes free energy value decreases to $31.13 \mathrm{~kJ} / \mathrm{mol}$ for $\mathbf{T S b}(\mathbf{R})$ as the consequence of the unfavorable positive activation entropy $(\Delta \mathrm{S}=11.37 \mathrm{~J} / \mathrm{mol}$. Thus, these values predict the same finding in therm of predominance of $S$ selectivity obtained in electronic energies. Furthermore, this 22CA reaction is strongly exergonic by between 52.92 and $23.36 \mathrm{~kJ} / \mathrm{mol}$. Consequently, the $\mathbf{M 5 a}(\mathbf{S})$ is clearly the most favorable product to obtain over the $\operatorname{M5a}(\mathbf{R})(\Delta \Delta \mathrm{G}=6.59 \mathrm{~kJ} / \mathrm{mol})$ under both kinetic and thermodynamic controls (see Fig 4, Table 6).

Table 6: MPWB1K/6-31G(d,p) enthalpies (H, in a.u.), entropies (S, in cal /mol K) and Gibbs free energies (G, in a.u.), and the relative a ones $(\Delta \mathrm{H}$ in $\mathrm{kJ} / \mathrm{mol}, \Delta \mathrm{S}$ in cal/ mol K and $\Delta \mathrm{G}$ in $\mathrm{kJ} / \mathrm{mol} \mathrm{K}$, respectively), computed at 398.15 $\mathrm{K}$ and $1 \mathrm{~atm}$, for the TSs involved in the [2+2] cycloaddition reaction along the along the reaction pathways (a and b).

\begin{tabular}{|c|c|c|c|c|c|c|}
\hline System & $\mathbf{H}$ & $\Delta \mathbf{H}$ & $\mathbf{S}$ & $\Delta \mathbf{S}$ & G & $\Delta \mathbf{G}$ \\
\hline M1a(S) & -1032.685540 & & 169.187 & & -1032.765886 & \\
\hline $\operatorname{M1a}(\mathbf{R})$ & -1032.686574 & & 163.746 & & -1032.764336 & \\
\hline M1b(S) & -1032.696022 & & 165.501 & & -1032.774617 & \\
\hline $\operatorname{M1b}(\mathbf{R})$ & -1032.700962 & & 165.706 & & -1032.779654 & \\
\hline
\end{tabular}




\begin{tabular}{ccccccc}
$\mathbf{T S a}(\mathbf{S})$ & -1032.682125 & 8.97 & 165.857 & -3.33 & -1032.760889 & 13.12 \\
$\mathbf{T S a}(\mathbf{R})$ & -1032.681966 & 11.68 & 157.433 & -6.31 & -1032.756730 & 19.97 \\
$\mathbf{T S b}(\mathbf{S})$ & -1032.681897 & 37.08 & 161.614 & -3.89 & -1032.758646 & 41.93 \\
$\mathbf{T S b}(\mathbf{R})$ & -1032.687815 & 34.52 & 168.422 & 2.72 & -1032.767798 & 31.13 \\
$\mathbf{M 2 a}(\mathbf{S})$ & -1032.709272 & -62.31 & 161.655 & -7.53 & -1032.786041 & -52.92 \\
$\mathbf{M 2 a}(\mathbf{R})$ & -1032.707172 & -54.08 & 157.529 & -6.22 & -1032.781982 & -46.33 \\
$\mathbf{M 2 b}(\mathbf{S})$ & -1032.712759 & -43.94 & 152.098 & -13.40 & -1032.784989 & -27.23 \\
$\mathbf{M 2 b}(\mathbf{R})$ & -1032.712190 & -29.48 & 160.795 & -4.91 & -1032.788550 & -23.36 \\
\hline
\end{tabular}
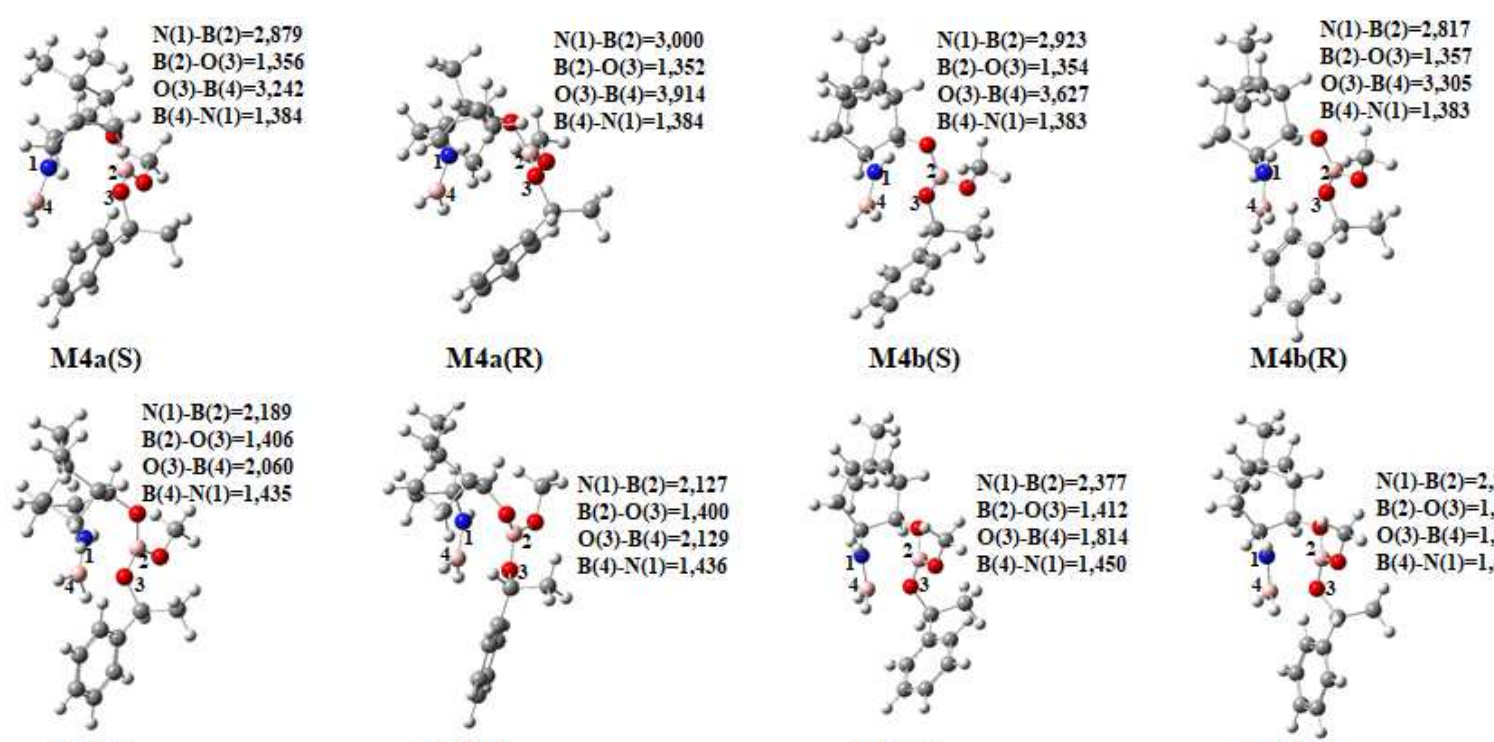

$\mathrm{TSa}(\mathrm{S})$
$\mathrm{N}(1)-\mathrm{B}(2)=1,600$

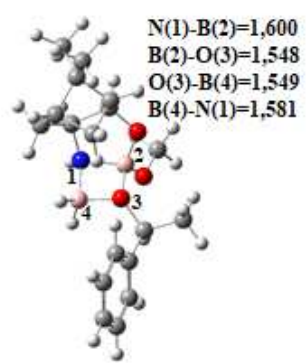

$\mathrm{TSa}(\mathrm{R})$

$\operatorname{TSb}(\mathbf{S})$
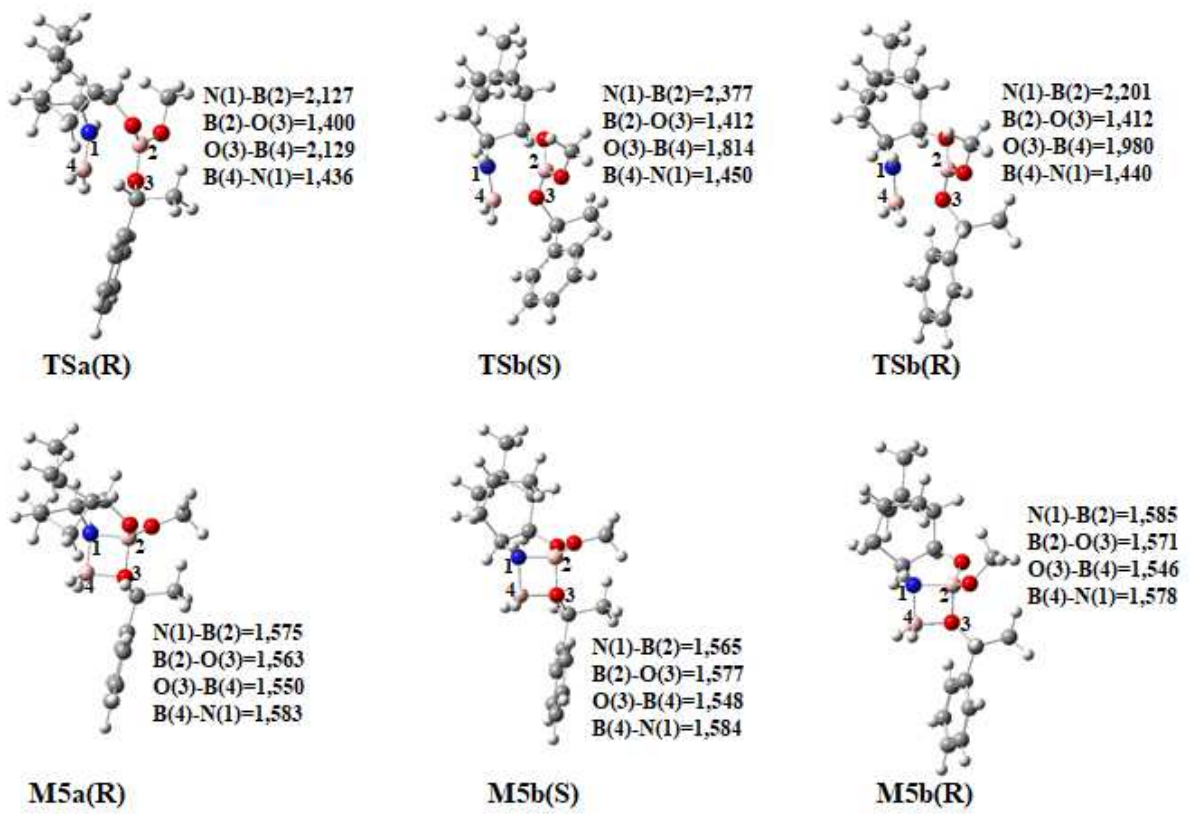

Fig. 3 The MPWB1K/6-31G(d,p) optimized structures for complexes M4(aS,aR,bS,bR), M5(aS,aR,bS,bR) and transition states TS (aS,aR,bS,bR) involved in the 22CA step (unit in $\AA$ for bond lengths) 




Fig. 4 Gibbs free energy profile $\left(\Delta \mathrm{G}\right.$, in $\left.\mathrm{kJ} \mathrm{mol}^{-1}\right)$ of the 22CA step of the reduction of acetophenone with borane catalyzed by a $B$-methoxy oxazaborolidine 
3.4. Nature of molecular mechanism (ELF analysis):

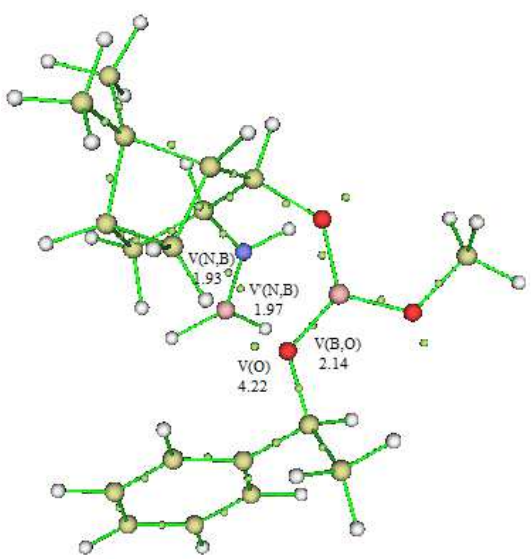

$\mathrm{M} 4 \mathrm{a}(\mathrm{S})$

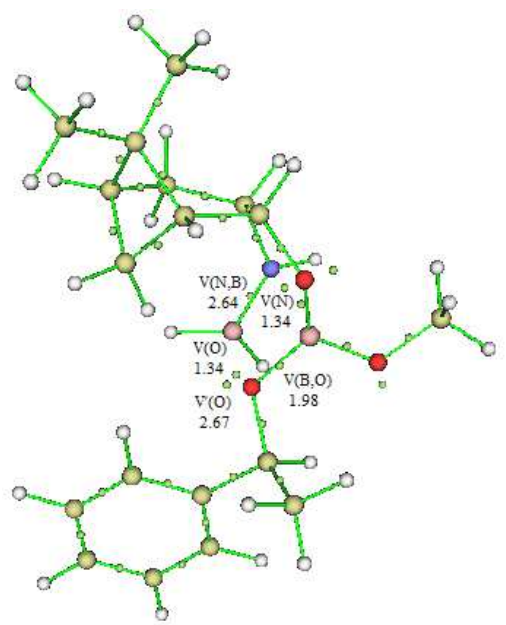

P2

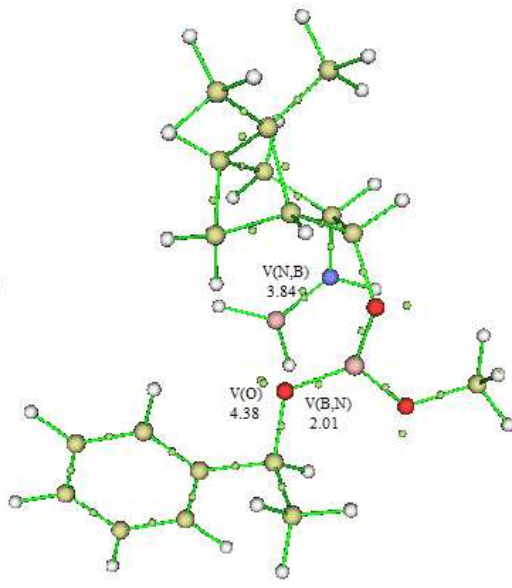

Pl

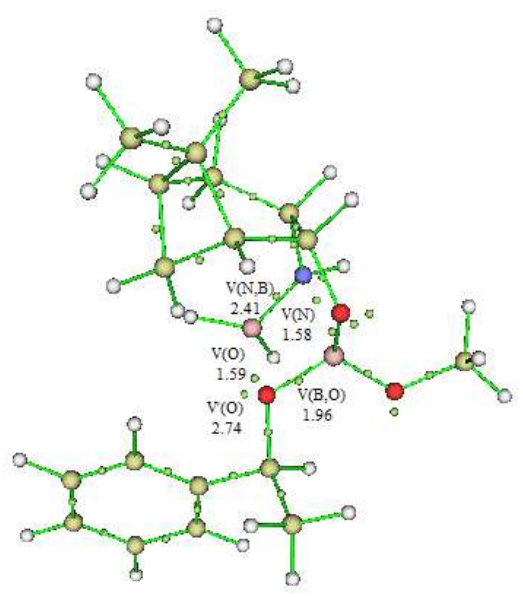

P3
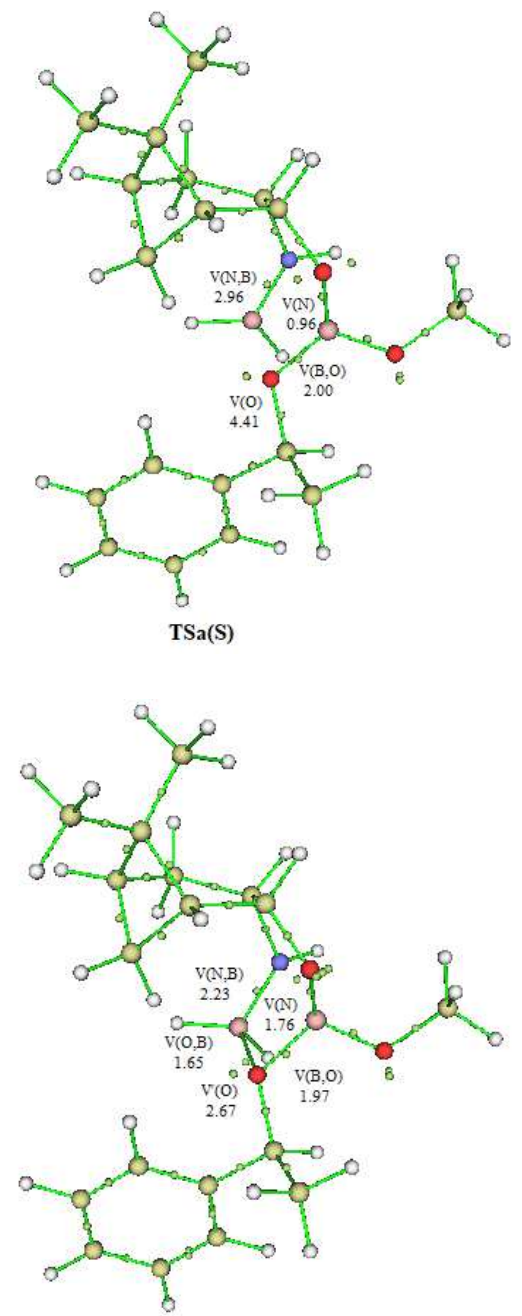

P4 

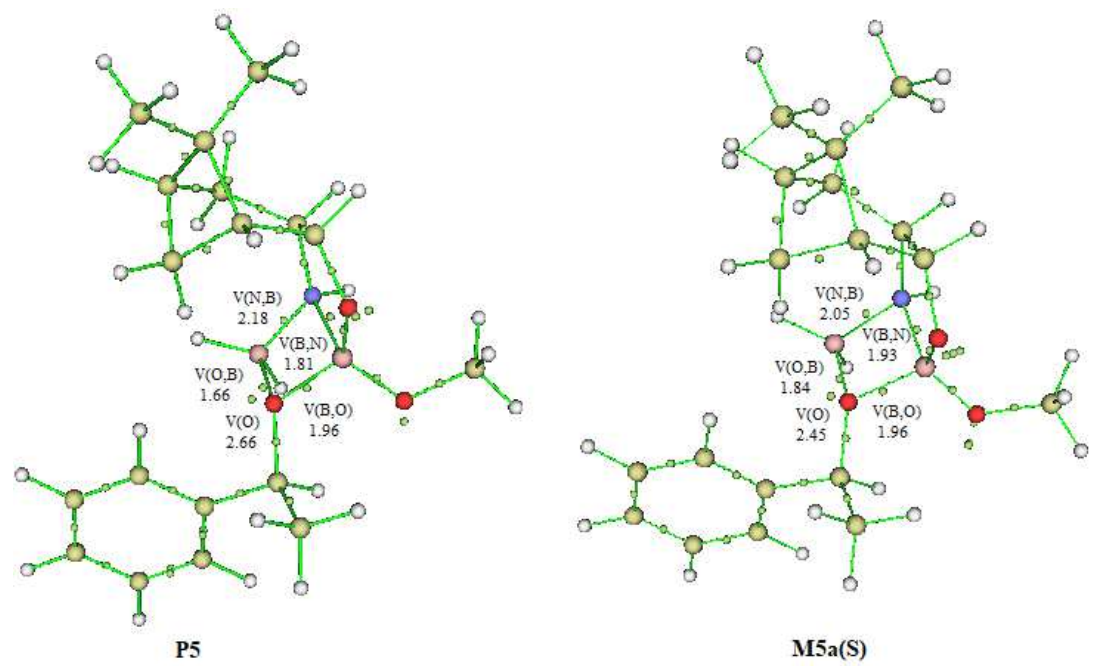

Fig. 5 Electron localisation function basin attractor positions of the relevant points of IRC $\mathbf{M} 4 \mathbf{a}(S)-M 5 a(S)$ related to the formation of the N-B and O-B bonds along the most favorable $\mathbf{T S a}(S)$

In order to gain insight on the most significant bonding changes along the reaction path of 22CA step of the most favorable transition state $\mathbf{T S a}(\boldsymbol{S})$, by characterizing the electronic structures in which the reactivity and electronic structure of 22CA can be linked with each other, an ELF ${ }^{34,35}$ topological analysis of some appropriate path selected from IRC related to the formation of $\mathbf{M 5 a}(S)$ complex, was performed to calculate basins of attractors with the most representative valence basin populations of 22CA reaction. That is the space in which the probability of finding an electron pair is maximal ${ }^{36}$. The valence basin populations ELF analysis of the selected structures associated with the formation of the O-B and N-B single bonds along the IRC of $\operatorname{M4a}(S)-M 5 a(S)$, and their electronic population and position are shown in Fig 5.

The ELF analysis of $\mathbf{M 4 a}(S), d(\mathrm{~B}, \mathrm{~N})=2.87 \AA$ and $d(\mathrm{O}, \mathrm{B})=3.24 \AA$, point out the presence of the following basins: two disynaptic basins $\mathrm{V}(\mathrm{N}, \mathrm{B})$ and $\mathrm{V}^{\prime}(\mathrm{N}, \mathrm{B})$ related to the N-B bonding region, integrating 1.93 e and 1.97 e respectively, as well as one monosynaptic basin $\mathrm{V}(\mathrm{B}, \mathrm{O})$ with a population of $2.14 \mathrm{e}$ belonging to $\mathrm{B}-\mathrm{O}$ single bond, and one monosynaptic basin $\mathrm{V}(\mathrm{O})$ integrating $4.22 \mathrm{e}$ associated with oxygen lone pair electron density at oxygen moiety.

ELF of P1 $d(\mathrm{~B}, \mathrm{~N})=2.40 \AA$ and $d(\mathrm{O}, \mathrm{B})=2.35 \AA$, illustrates an increase of both $\mathrm{V}(\mathrm{N}, \mathrm{B})$ and $\mathrm{V}^{\prime}(\mathrm{N}, \mathrm{B})$ disynaptic basins to $3.84 \mathrm{e}$ for each one, while $\mathrm{V}(\mathrm{B}, \mathrm{O})$ monosynaptic basin decreases to a population of 2.01e. Noticeably, the monosynaptic basin $\mathrm{V}(\mathrm{O})$ shown in $\mathbf{M} 4 \mathbf{a}(\boldsymbol{S})$ experiences a split into two disynaptic basines $\mathrm{V}(\mathrm{O})$ and $\mathrm{V}^{\prime}(\mathrm{O})$ integrating $4.38 \mathrm{e}$ for each one. 
In $\mathbf{T S a}(S), d(\mathrm{~B}, \mathrm{~N})=2.18 \AA$ and $d(\mathrm{O}, \mathrm{B})=2.07 \AA$, the most relevant change of this TS is the appearance of a new $\mathrm{V}(\mathrm{N})$ monosynaptic basin, integrating $0.96 \mathrm{e}$ which is an indicator for the beginning of the creation of the $\mathrm{N}$ lone pair. Meanwhile, the $\mathrm{V}(\mathrm{N}, \mathrm{B})$ and $\mathrm{V}^{\prime}(\mathrm{N}, \mathrm{B})$ disynaptic basins gathered into one $\mathrm{V}(\mathrm{N}, \mathrm{B})$ monosynaptic basin with decrease of population towards 2.96 e. Whereas the pair disynaptic basins $\mathrm{V}(\mathrm{O})$ and $\mathrm{V}^{\prime}(\mathrm{O})$ appeared in $\mathbf{P 1}$ are merged into one monosynaptic $\mathrm{V}(\mathrm{O})$ with a population of $4.41 \mathrm{e}$, while $\mathrm{V}(\mathrm{B}, \mathrm{O})$ monosynaptic basin remain almost unchanged with a population of $2.00 \mathrm{e}$.

In $\mathbf{P 2}, d(\mathrm{~B}, \mathrm{O})=1.94 \AA$ and $d(\mathrm{~N}, \mathrm{~B})=2.07 \AA$, the monosynaptic basin $\mathrm{V}(\mathrm{O})$ present at $\mathbf{T S a}(S)$ split again into two $\mathrm{V}(\mathrm{O})$ and $\mathrm{V}^{\prime}(\mathrm{O})$ integrating $1.34 \mathrm{e}$ and $2.76 \mathrm{e}$, respectively. Whereas, the $\mathrm{V}(\mathrm{N})$ monosynaptic basin formed at $\mathrm{TSa}(\mathrm{S})$ has increased to $1.34 \mathrm{e}$, as a result of the depopulation of $\mathrm{V}(\mathrm{N}, \mathrm{B})$ disynaptic basin to $2.64 \mathrm{e}$.

In P3, $d(\mathrm{~B}, \mathrm{O})=1.83 \AA$ and $d(\mathrm{~N}, \mathrm{~B})=1.94 \AA$, several topological significant changes are observed related to the creation of the O-B and N-B single bonds: at the first most relevant topological change, the $\mathrm{V}(\mathrm{O})$ monosynaptic associated with one of the two non- bonding $\mathrm{O}$ lone pair experiences an increase of its population to achieve $1.59 \mathrm{e}$, which is necessary for the creation of an O-B bond. At the same time, the population of the $\mathrm{V}(\mathrm{N})$ monosynaptic basin related to the nitrogen $\mathrm{N}$ lone pair continues to profit to more electron population reaching $1.58 \mathrm{e}$, as a consequence of the depopulation of $\mathrm{eV}(\mathrm{N}, \mathrm{B})$ to $2.41 \mathrm{e}$, this second topology change is demanded for the formation of the second single bond N-B. Whereas, the population of the $\mathrm{V}(\mathrm{B}, \mathrm{O})$ disynaptic basin decreases slightly to achieve $1.98 \mathrm{e}$ and $1.96 \mathrm{e}$, respectively.

ELF of $\mathbf{P 4}, d(\mathrm{~B}, \mathrm{~N})=1.81 \AA$ and $d(\mathrm{O}, \mathrm{B})=1.72 \AA$, shows a creation of a new $\mathrm{V}(\mathrm{O}, \mathrm{B})$ monosynaptic basin with an initial integration of $1.65 \mathrm{e}$, which account for the beginning of the formation of the first $\mathrm{O}-\mathrm{B}$ single bond (dative covalent bond) at a length of $c a 1.72 \AA$ through the total donation of the electron density of the non-bonding $\mathrm{sp}^{2}$-hybridised $\mathrm{O}$ lone pair to the empty orbital in the B atom. Meanwhile, the V(N,B) disynaptic basin continues depopulating allowing to the increase of $\mathrm{V}(\mathrm{N})$ monosynaptic basin to $1.76 \mathrm{e}$, which becomes almost lone pair.

In P5, the most noticeable change is related to the apparition of a new $\mathrm{V}(\mathrm{B}, \mathrm{N})$ disynaptic Basin with a population of 1.81e, indicating the begun of the formation of the second B-N single bond (dative covalent bond) at length of $c a 1.77 \AA$, in which the losing electron-density at $\mathrm{N}$ is totally gathered at this newest forming bond. Whereas, the population of the $\mathrm{V}(\mathrm{O}, \mathrm{B})$ disynaptic basin, associated with the first formed O-B bond, remains almost unchanged.

Finally, ELF of M5a $(S), d(\mathrm{~B}, \mathrm{~N})=2.40 \AA$ and $d(\mathrm{O}, \mathrm{B})=2.35 \AA$, illustrates an increase of the population of both disynaptic basins $\mathrm{V}(\mathrm{O}, \mathrm{B})$ and $\mathrm{V}(\mathrm{B}, \mathrm{N})$, to $1.84 \mathrm{e}$ and $1.93 \mathrm{e}$, 
respectively. The $\mathrm{V}(\mathrm{N}, \mathrm{B})$ disynaptic basin and the oxygen lone pair experience a decrease of their populations to reach $2.05 \mathrm{e}$ and $2.45 \mathrm{e}$, respectively.

ELF topological analysis related to the formation of both $\mathrm{B}-\mathrm{N}$ and N-B single bonds along the most favorable $\mathbf{T S a}(S)$, resumes some relevant points: (1) This reaction pathway occurs through a two-stage one-step mechanism, in which the B-O began somewhat before the formation of the second single bond N-B, which account for an almost asynchronous. (2) The formation of the two O-B and N-B single bonds takes place through the donation of the lone pair of $\mathrm{O}$ and $\mathrm{N}$ into the empty orbital in the $\mathrm{B}$.

\subsection{Origin of the $S$ selectivity for the a catalytic cycle}

\subsubsection{Non-Covalent Interactions in Transition States}

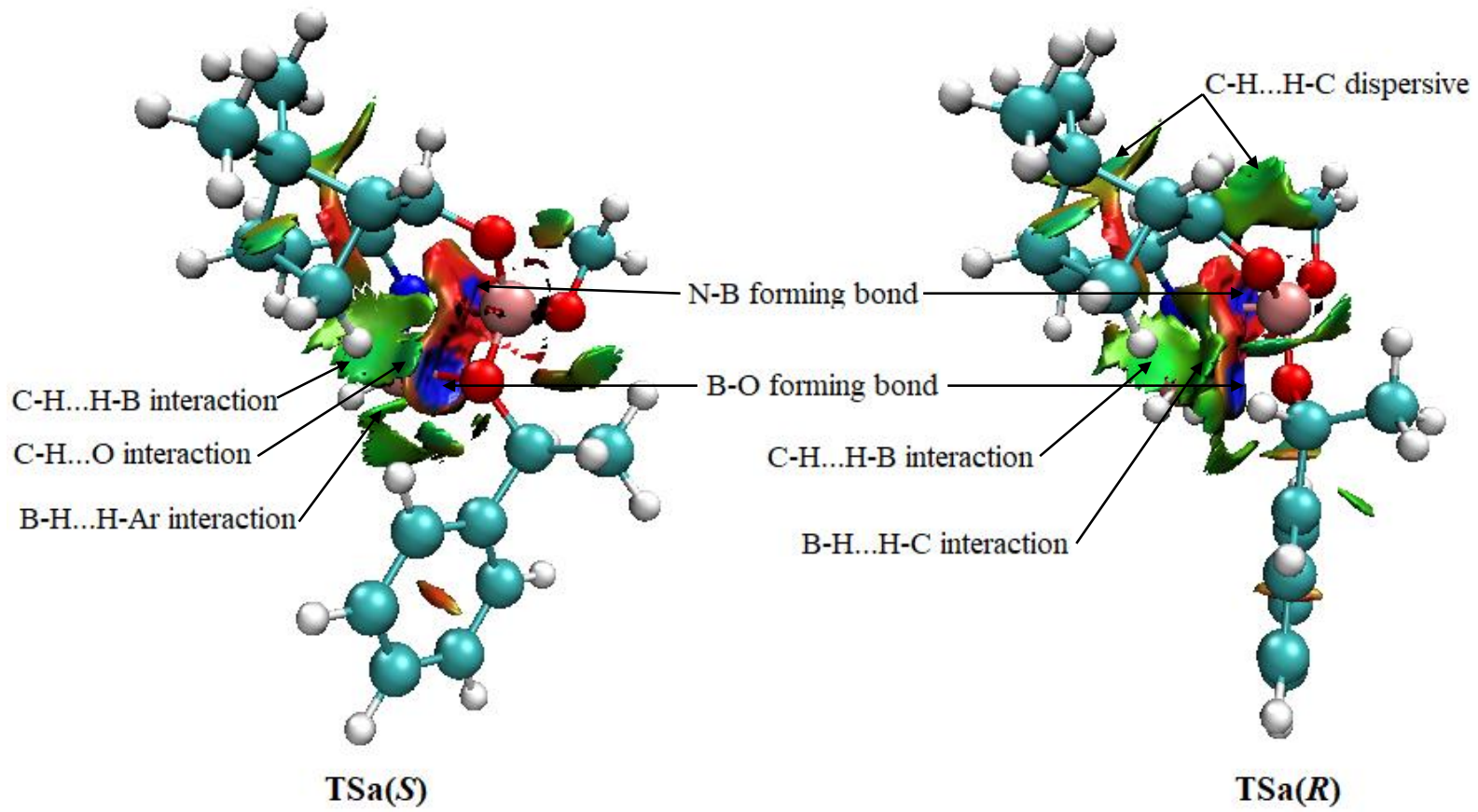

Fig. 6 NCI analysis of the MPWB1K/6-31G(d,p) optimised transition states $\mathbf{T S a}(S)$ and $\mathbf{T S a}(\boldsymbol{R})$. Blue for strong attractive, green for intermediate interactions.

Previous studies have illustrated that non-covalent interactions play an important role in determining the selectivity in the wide large of reactions ${ }^{7,37}$. Thus, for gain some 
insight into the origin of the $S$ selectivity obtained along the $\mathbf{T S a}(S)$, which implies to justify the stabilization of $\mathbf{T S a}(S)$ with respect to $\mathbf{T S a}(\boldsymbol{R})$. Thus, for explaining the stabilization of conformers and understanding of driving forces in our structures, a topological analysis NCI ${ }^{38}$ of the MPWB1K/6-31G(d,p) optimized TSs was highlighted in Fig 6. The deep blue region shown in both TSs reveals that the forming N(1)-B(2) and $\mathrm{O}(3)-\mathrm{B}(4)$ bonds are on the border of covalent, and non covalent. Along with the N(1)$\mathrm{B}(2)$ and $\mathrm{O}(3)-\mathrm{B}(4)$ formation, both TSs undergo other common HBs interactions, which comes mainly from the orientation of the methanediyl group inside the pinene skeleton towards atoms below. For the lowest-energy transition state $\mathbf{T S a}(\boldsymbol{S})$, NCI plot (Fig 6) discloses three interactions involving $\mathrm{H}$ atom of the methanediyl: one located with $\mathrm{H}$ attached to boron atom, the second interaction occurs with the hydrogen of the aromatic ring of acetophenone and the third one done with the oxygen atom of oxazaborolidine, this latest interaction is more conducive to stabilizing the conformer. Whereas in $\mathbf{T S a}(\boldsymbol{R})$, there are only two weak interactions: $\mathrm{C}-\mathrm{H} \ldots \mathrm{H}-\mathrm{B}$ and $\mathrm{CH}_{2}-\mathrm{H} \ldots \mathrm{H}-\mathrm{CH}_{2}$. It's worth noting that all those hydrogen and dihydrogen bond interactions are validated by the presence of surfaces coloured with light and bluish green which indicates a weak to moderately strong attraction.

Consequently, the presence of more HBs interactions in $\mathbf{T S a}(\boldsymbol{S})$ with respect to $\operatorname{TSa}(\boldsymbol{R})$ supports a favorable conformation of the $\mathbf{T S 3 a}(S)$, for giving the $S$ chirality of the product along the a cycle, which is in-line with what it was evoked above.

\subsubsection{Quantum Theory of Atoms in Molecules (QTAIM) Analysis}

In order to deeply understand the difference in the amount of interaction shown in previously NCI study with both $\mathbf{T S a}(S)$ and $\mathbf{T S a}(\boldsymbol{R})$ and be more accurate with what is evoked in NCI analysis, we have performed a QTAIM topological analysis to shed light into conventional and non-conventional HB.

It has been suggested that QTAIM is a powerful tool to characterize hydrogen bonding interactions by correlation between electron density $\rho$ at bond critical points and bond strength, which provides a series of critical points (cp). The existence of the binding interaction independent the nature bond is conditioned by the presence of $\mathrm{CP}(3,-1)$. Whereas, the Laplacian of the electron density in a bond critical point, $\nabla^{2} \rho_{b c p}$, plays a great role in determining electron density concentration in the interatomic space, which is measured on the basis of the value and the sign of Laplacien, where the positive sign of the Laplacian $\nabla^{2} \rho_{b c p}$ 
in the BCP is attributed to closed-shell-interaction, such as hydrogen where the electron density for this interaction is locally depleted, while the negative one is related to sharedinteraction like covalent bonds as a consequence of a local concentration of $\rho_{b c p}$. Thus, the Laplacian electron density and electron energy density as a criterion of hydrogen bonds description was proposed

1) $\nabla^{2} \rho_{b c p}<0, H_{c b c p}<0 \quad$ - strong typ interactions like weakly polar covalent bonds.

2) $\nabla^{2} \rho_{b c p}>0, H_{c b c p}<0$ - medium typ interactions like strong hydrogen bonds and polar covalent bonds.

3) $\nabla^{2} \rho_{b c p}>0, H_{b c p}>0$ - weak typ interactions like Van der Waals bonds and weak hydrogen bonds.

As illustrated in Table 7, Topological parameters and intramolecular hydrogen bond energies of $\mathbf{T S a}(\mathbf{S})$ and $\mathbf{T S a}(\mathbf{R})$ are compared. The Laplacian and electron energy of the new forming bonds B...O and N...B demonstrates that is intermediary non-covalent interactions present within the backbone of both TSs which is characterized by $\nabla^{2} \rho_{b c p}>0$ and $H_{b c p}<0$ that is evidence of the closed-shell interaction. Moreover, the $\mathrm{H}(\mathrm{r})$ value in the B...O bond at $\mathbf{T S a}(\mathbf{S})$ is considerably more negative $(\mathrm{H}(\mathrm{r})=-0.105 \mathrm{au})$ than that in the $\mathrm{B} \ldots \mathrm{N}(\mathrm{H}(\mathrm{r})=$ $-0.705 \mathrm{au}$ ) bond which makes the former interaction stronger than the latter one. Whereas, at $\mathbf{T S a}(\mathbf{R})$ the interaction in newly forming bond $\mathrm{B} \ldots \mathrm{N}(\mathrm{H}(\mathrm{r})=-0.1405 \mathrm{au})$ is stronger than that in $\mathrm{B} \ldots \mathrm{O}(\mathrm{H}(\mathrm{r})=-0864 \mathrm{au})$. Resulting, a more strength of the newly forming bond $\mathrm{B} \ldots \mathrm{O}$ in $\mathbf{T S a}(\mathbf{S})$ than N...B forming bond in $\mathbf{T S a}(\mathbf{R})$ as $H(r)_{B \ldots O}>H(r)_{N \ldots B}$. Additionally, beside to weak stabilized non-conventional H...H interactions pointed out by $\nabla^{2} \rho_{b c p}>0$ and $H_{b c p}>0$ of $(3,-1)$ bcp which has been seen in both TSs, another type of hydrogen bond associated with $\mathbf{T S a}(\mathbf{S})$ is found between $\mathrm{H} . . \mathrm{O}$ characterized by small $\rho_{H \ldots O}$ values together with positive Laplacian which is a sign of closed-shell interactions observed in $\mathrm{H}$-bond. Consequently, these interactions are significantly stabilising $\mathbf{T S a}(\mathbf{S})$ over $\mathbf{T S a}(\mathbf{R})$, which is inline with what has been found above. 


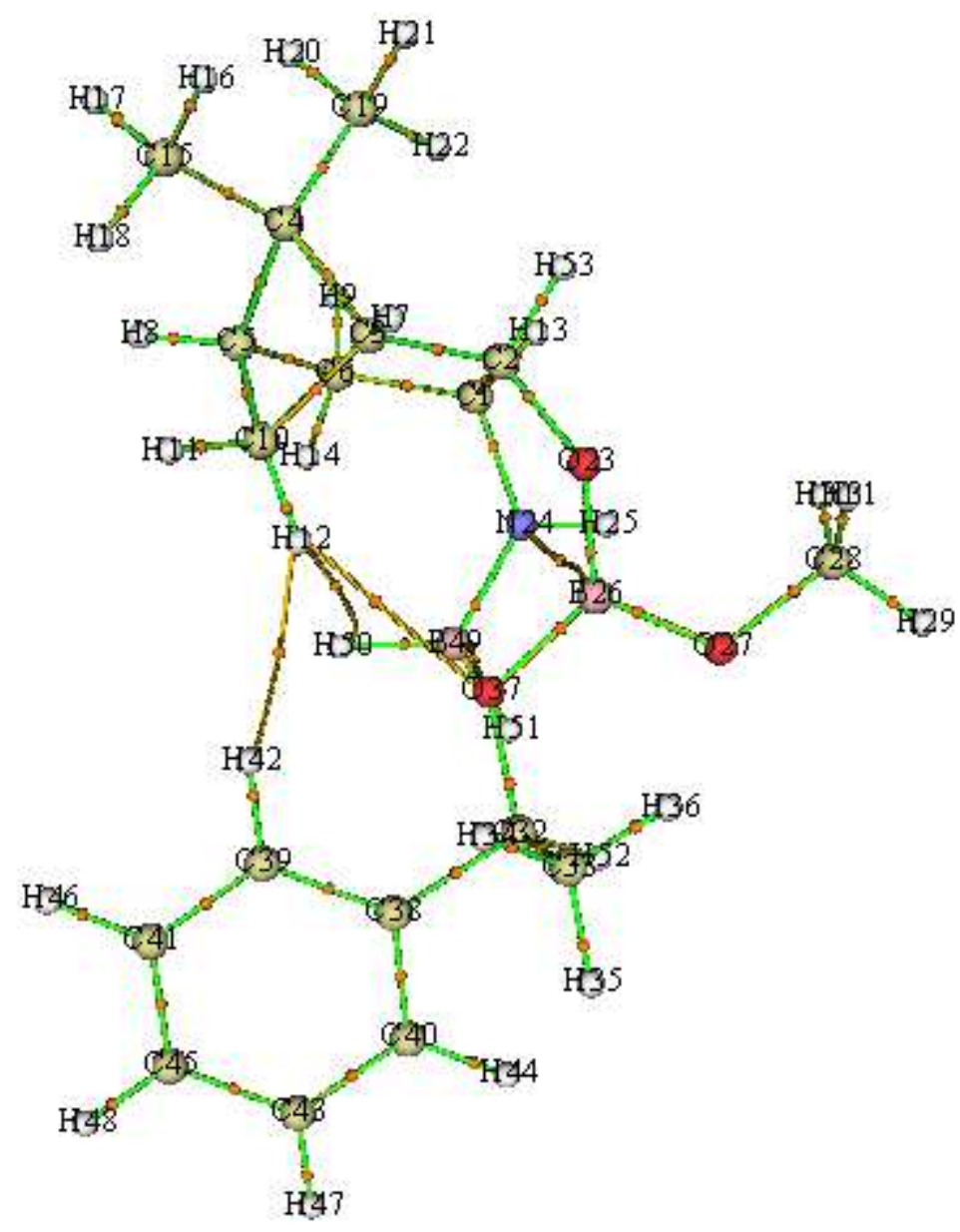

TSa(S) 


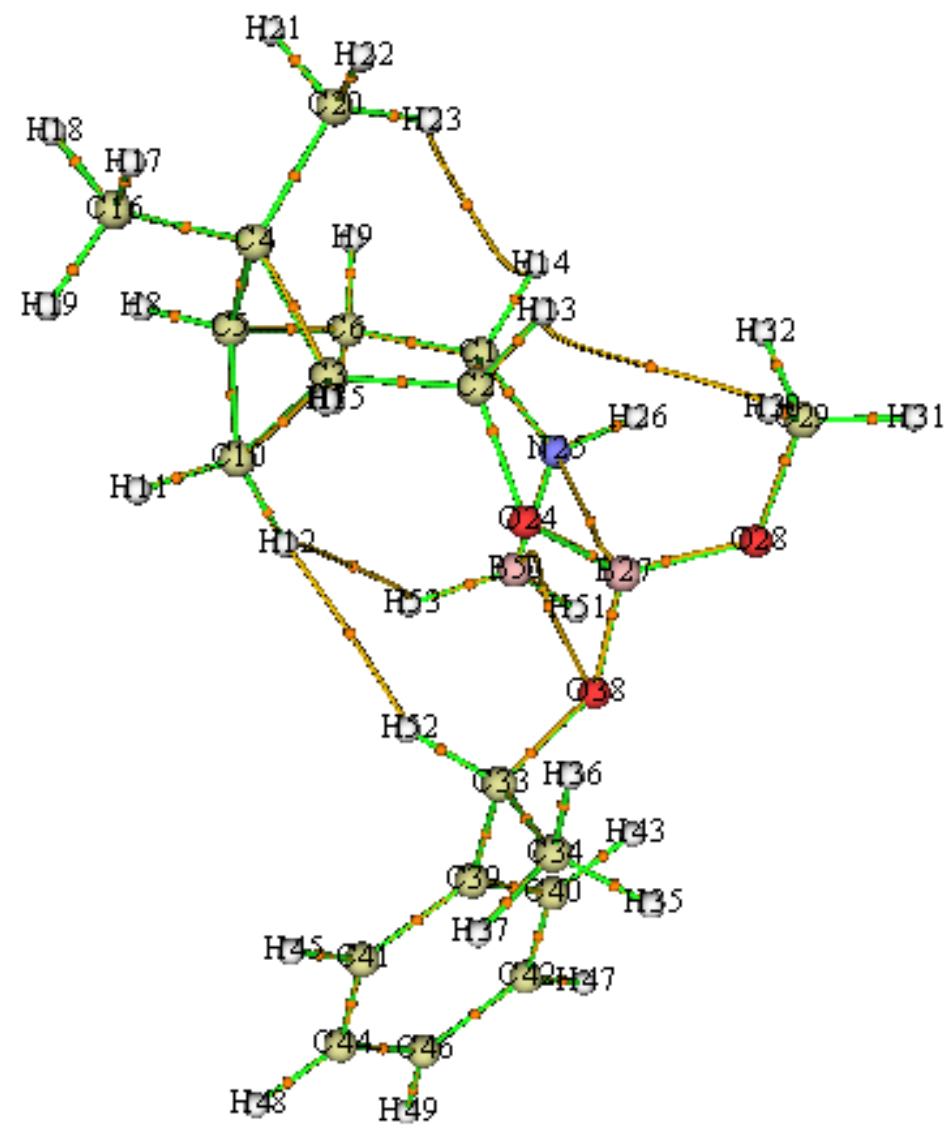

TSa(R)

Table7 QTAIM parameters/ a.u of the $(3,-1)$ bond critical points for $\operatorname{TSa}(S)$ and $\mathbf{T S a}(\boldsymbol{R})$. Wavefunctions are obtained at the MPWB1K level using 6-31G (d,p) basis set.

\begin{tabular}{cccccc}
\hline & interaction & BCP & $\rho_{\text {cbcp }}$ & $\nabla^{2} \rho_{b c p}$ & $\mathrm{H}_{\mathrm{bcp}}$ \\
\hline TSa(S) & $\mathrm{H}(42)-\mathrm{H}(12)$ & 70 & 0.439 & 0.900 & 0.137 \\
& $\mathrm{H}(12)-\mathrm{H}(50)$ & 77 & 0.939 & 0.374 & 0.216 \\
& $\mathrm{H}(12)-\mathrm{O}(37)$ & 87 & 0.102 & 0.374 & 0.948 \\
& $\mathrm{~N}(24)-\mathrm{B}(26)$ & 112 & 0.394 & 0.632 & -0.705 \\
$\mathbf{T S a}(\mathbf{R})$ & $\mathrm{B}(49)-\mathrm{O}(37)$ & 96 & 0.422 & 0.211 & -0.105 \\
& $\mathrm{H}(13)-\mathrm{H}(30)$ & 121 & 0.822 & 0.356 & 0.203 \\
& $\mathrm{H}(23)-\mathrm{H}(14)$ & 108 & 0.128 & 0.507 & 0.223 \\
& $\mathrm{H}(12)-\mathrm{H}(53)$ & 70 & 0.799 & 0.258 & 0.134 \\
& $\mathrm{H}(12)-\mathrm{H}(52)$ & 76 & 0.653 & 0.226 & 0.118 \\
& $\mathrm{~N}(25)-\mathrm{B}(27)$ & 112 & 0.475 & 0.561 & -0.140 \\
& $\mathrm{~B}(50)-\mathrm{O}(38)$ & 100 & 0.373 & 0.717 & -0.864 \\
\hline
\end{tabular}




\section{Conclusions}

This work has studied, using MPWB1K/6-31G(d,p) DFT methods, the [2+2] cycloaddition step involved in the mechanism reactional of the enantioselective reduction of ketones with borane catalyzed by a $B$-methoxy oxazaborolidine catalyst derived from (-)- $\beta$ Pinene. Thus, The calculated results indicate that this reaction takes place through four transition steps $\mathbf{T S a}(\mathbf{S}), \mathbf{T S a}(\mathbf{R}), \mathbf{T S b}(\mathbf{S})$ and $\mathbf{T S b}(\mathbf{R})$, where the mode a denotes the implication of the kind a of oxazaborolidine, while the $\mathbf{b}$ one refers to the implication of $\mathbf{b}$ kind). The following findings can be drawn from our results:

1. Houk's rule and FMO studies show that intramolecular cycloaddition reaction takes place between the fragment $\mathbf{B}$ which act as nucleophile whereas the fragment A considered as electrophile, where the most favored large-large interaction occurs between $\mathrm{O}(3)$ of fragment $\mathrm{B}$ and $\mathrm{B}(4)$ of the fragment $\mathbf{A}$, while the small-small interaction done between $\mathrm{B}(2)$ of the fragment $\mathbf{B}$ and $\mathrm{N}(1)$ of the fragment $\mathbf{A}$.

2. $\mathbf{T S a}(\mathbf{S})$ is kinetically and thermodynamically the most favorable transition state relative to $\mathbf{T S a}(\mathbf{R}), \mathbf{T S b}(\mathbf{S})$ and $\mathbf{T S b}(\mathbf{R})$, thus, the chirality of the reduced products in this step is of $S$ type, which is consistent with the experimental outcomes.

3. ELF topological analysis during the formation of the two new single bonds N...B and $\mathrm{B} \ldots \mathrm{O}$ with the more stable $\mathrm{TSa}(\mathrm{S})$ involved in the 22CA step of the enantioselective reduction of ketones with borane catalyzed by a B-methoxy oxazaborolidine, illustrates that the reaction intramolecular between the fragment A and fragment $\mathrm{B}$ occurs at a distance of $c a 1.72$ through the total donation of the electron density of the non-bonding $\mathrm{sp}^{2}$-hybridised $\mathrm{O}$ lone pair to the empty orbital in the B atom, while the formation of the second N...B single bond takes place at a distance of $c a 1.77$, where the losing electron-density at $\mathrm{N}$ is totally gathered at this newest forming bond. Thus, the formation of an O-B single bond precedes the formation of N-O, supporting two-stage-one step mechanism.

4. The NCI (Non Covalent Interaction) and QTAIM study of the most favorable transition state $\mathbf{T S a}(S)$ suggests the presence of moderately strong interaction between the $\mathrm{H}$ atom of the methanediyl group inside the pinene skeleton and the oxygen atom of the oxazaborolidine ring, which accounts for the stabilisation of the $\mathbf{T S a}(\boldsymbol{S})$ with respect to $\mathbf{T S a}(\boldsymbol{R})$, explaining that the $S$ selectivity obtained in this step is aligned with the chirality of the whole step of the reaction mechanism. 
Funding: N/A

Availability of data and material: The datasets used or analyzed during the current study are available from the corresponding author on reason-able request

Code availability: $\quad$ N/A

Authors' contributions: N/A

Declarations

Conflicts of interest: I declare that I have no conflict of

interest.

\section{References}

1. (a) Hirao A, Itsuno S, Nakahama S, Yamazaki N. J. Chem. Soc., Chem. Commun. 1981, 0, 315-317. (b)

Hirao A, Itsuno S, Nakahama S. ; Ito K. J. Chem. Soc., Chem. Commun. 1983, 0, 469-470.S.

2. (a) Corey EJ, Bakshi RK, Shibata S. J.Am. Chem. Soc. 1987,109, 5551.(b) Corey EJ, Bakshi RK.,

Shibata S, Chen CP, Singh VK. J. Am. Chem. Soc. 1987,109, 7925-7926.(c) Corey,E. J.; Shibata,

S.;Bakshi RK. J. Org. Chem. 1988,53,2861.(d) Corey EJ, Helal CJ. Angew. Chem. Int. Ed. 1998, 37 1986-2012.

3. (a) Wallbaum S, Martens J. Tetrahedron :Asymmetry. 1992, 3, 1475-1504 ; (b). Singh VK. Synthesis.1992, 605 ; (c) Deloux L, Srebnik M. Chem. Rev. 1993, 93,763 ; (d) Corey EJ, Helal CJ. Angew. Chem. Int. Ed. Engl. 1998, 37,1986.

4. Masui M, Shioiri T. Synlett 1997, 273-274.

5. Wei D, Tang M, Zhao J, Sun L, Zhang W, Zhao C, Zhang S, Wang H . Tetrahedron: Asymmetry. 2009, 20, 1020-1026

6. Sun L, Tang M, Wang H, Wei D, Liu L. Tetrahedron: Asymmetry. 2008 , 19, 779-787

7. Kettouche H S. Journal of Molecular Modeling. 2020, 26:27.

8. Becke AD, Edgecombe KE. J. Chem. Phys. 1990, $925397 \mathrm{e} 5403$.

9. Contreras-García J, Johnson ER, Keinan S, Chaudert R, Piquemal JP, Beratan DN, Yang W. NCIPLOT: a program for plotting noncovalent interaction regions, J. Chem. Theory Comput. $2011,7625-$ 632

10. Bader RFW. Atoms in Molecules: a Quantum Theory, Oxford University Press, Oxford, 1990.

11. Frisch MJ. Gaussian 09, Revision A.02; Gaussian: Wallingford, CT, 2009.

12. Lynch BJ, Fast PL, Harris M and Truhlar DG. J. Phys. Chem. A, 2000, 104, 4811.

13. Hehre W J, Radom L, Schleyer PVR and Pople JA., Ab Initio Molecular Orbital Theory, Wiley, New York, NY, 1986.

14. Lee C, Yang W and Parr RG. Phys. Rev. B: Condens. Matter Mater. Phys., 1988, 37, 785.

15. Becke AD. J. Chem. Phys., 1993, 98, 5648.

16. Zhao Y, Truhlar DG. The M06 Suite of Density Functionalsfor Main Group Thermochemistry, Thermochemical Kinetics, Non-covalent Interactions, Excited States, and Transition Elements.Theor.Chem. .Acc.2008,120, 215-241.

17. Gonzalez C, Schlegel HB. J. Phys. Chem. 1990, 94, 5523-5527.

18. Gonzalez C, Schlegel HB. J. Chem. Phys. 1989, 90, 2154-2161.

19. (a) Tomasi J, Mennucci B and Cancès E. J. Mol. Struct.: THEOCHEM, 1999, 464(1), 211-226 (b) SangAroon W and Ruangpornvisuti V. Int. J. Quantum Chem, 2008, 108(6),1181-1188

20. (a) Parr RG, Pearson RG. J. Am. Chem. Soc. 1983, 105, 7512; (b) Parr RG, Yang W. Density Functional Theory of Atoms and Molecules; Oxford University Press: New York, NY, 1989.

21. Parr RG, von Szentpaly L, Liu S. J. Am. Chem. Soc. 1999, 121, 1922.

22. Hehre WJ, Radom L, Schleyer PVR. and Pople JA. Ab Initio Molecular Orbital Theory, Wiley, New York, NY, 1986.

23. Becke AD, Edgecombe KE. J Chem Phys 1990, 92:5397-5403

24. Johnson ER, Keinan S, Mori-Sanchez P, Contreras-Garcia J, Cohen J, Yang AW. J Am Chem Soc 2010, 132:6498

25. Lane JR, Contreras-Garcia J, Piquemal JP, Miller BJ, Kjaergaard HGJ . Chem Theory Comput , 2013, 9:3263

26. Contreras-Garcia JE, Johnson R, Keinan S, Chaudret R, Piquemal JP, Beratan DN, Yang W. J Chem Theory Comput 2011,7:625 
27. Lu T, Chen F. Multiwfn: a multifunctional wavefunction analyzer. J. Comput. Chem. 2012, 33, 580-592.

28. Humphrey W, Dalke A, Schulten KVMD: visual molecular dynamics. J. Mol. Graphics 1996, 14, 33-38.

29. Bader RFW. Atoms in molecules. A quantum theory. Claredon Press, Oxford 1990

30. Tachibana A. Theor. Chem. Acc., 1999,102, 188.

31. Tachibana A, Parr RG., Int. J. Quantum Chem., 1992,41, 527.

32. Tachibana A. Int. J. Quantum Chem., 1996,57, 423.

33. Houk K.N. Acc. Chem. Res. 1975, 8, 361.

34. Domingo LR and Emamian SR., Tetrahedron, 2014, 70, 1267-1273.

35. Domingo LR, Ríos-Gutiérrez M and Pérez P. Tetrahedron, 2016, 72, 1524-1532.

36. Savin A. J. Chem. Sci., 2005, 117, 473.

37. Ríos-Gutiérrez M, Nasri L, Khorief Nacereddine A, Djerourou A, Domingo LR. J. Phys Org Chem, 2018 31:e3830.

38. Johnson ER, Keinan S, Mori-Sanchez P, Contreras-Garcia J, Cohen J, Yang AW. J Am Chem Soc, 2010 132:6498 



\section{Supplementary Files}

This is a list of supplementary files associated with this preprint. Click to download.

- Graficabstract.docx

- SupplimentarydataPubHichem2021finalSTUC.docx 